\title{
Chapter 15 \\ Setting the Scene: How to Enhance \\ the Knowledge and Practice \\ of Transformation Literacy
}

\author{
Petra Kuenkel
}

\begin{abstract}
This chapter looks at the scale and modes of transformations needed toward regenerative civilizations. Societal transformations have always happened in human history, and many have been consciously and actively promoted. What is new about the situation at the beginning of the twenty-first century is both scale and depth of transformations required. Institutional and political structures on which our globalized current systems are built, tend to perpetuate the status quo. It is therefore important to create new strategic and communicative structures in the form of crosssector and cross-institutional collaboration that initiate and facilitate transformations. The chapter suggests that transformation agents need to act more consciously as part of transformation systems around issues such as climate protection, regenerative pathways and economic systems change. The chapter elaborates three strategic core approaches that require conscious attention in transformation literacy: Collective stewardship as the pro-active engagement for a regenerative future in mutually supportive strategies; visionary multiplicity as the acknowledgment of plural approaches to the quality of life; and network leverage as the deliberate and reflective use of power across institutions. The chapter concludes with an overview of the different authors' chapters.
\end{abstract}

Keywords Systems aliveness $\cdot$ Transformation systems $\cdot$ Visionary multiplicity Network leverage $\cdot$ Healthy planet $\cdot$ Collective stewardship $\cdot$ Transformation literacy

\subsection{Introduction}

Societal transformations have always happened in human history, and many have been consciously and actively promoted. What is new about the situation at the beginning of the twenty-first century is both scale and depth. The scale of transformations needed - as the result of the impacts of climate change-is almost globally

\footnotetext{
P. Kuenkel $(\varangle)$

Collective Leadership Institute, Kurfürstenstr, 1, 14467 Potsdam, Germany

e-mail: petra.kuenkel@collectiveleadership.com
} 
acknowledged. No country, no government, no company and no citizen can escape climate change. But the depth of change needed is only partly accepted. While there is increasing realization that there is an intrinsic connection between the effects of global warming, biodiversity loss, global health threats, endangered natural habitats and widespread social inequity, the consequences of this realization are still widely ignored. This is not surprising as the institutional and political structures on which our globalized current systems are built on, tend to perpetuate the existence of the multi-faceted global arrangement that took us to the sustainability challenges we face. Most people working in these global to local institutional structures, are busy implementing their management tasks: the improvement of service delivery, the growth of their companies, the rescuing of people in need or the delivery of development. Some of the required transformative efforts get integrated in the management tasks: for example, the monitored steps toward environmental protection and ecosystems rehabilitation at different administrative government levels; the anchoring of sustainable development goals in company performance measures; the integration of social quality indicators as part of development efforts; or the reduction of pesticides in industrial agricultural practices. Other transformative efforts take place outside the dominant institutional structures, partly out of the frustration that change from within structures is too slow, partly, because transformative social innovations have always emerged from niches outside the mainstream (Verbong and Loorbach, 2012). Often, future visions and the practices that emerge from them, require the space of safe and like-minded communities, which build the momentum for elements of regenerative civilizations in mutual support. Multiple of such communities have emerged around sustainability transformations, economic systems change and regenerative practices. With a view to finding pathways toward regenerative civilizations such intentional communities are pioneers of the future as well as learning laboratories. In transformation as well as transition research, it is widely acknowledged that social change at scale requires top-down approaches, such as advanced and future-oriented policy decisions, and the connection and mutual learning of bottom-up approaches which model the societal, or even global change (Avelino et al., 2014; Loorbach et al., 2016; Rotmans \& Loorbach, 2010). It is important to note that in addition to administrative transformation efforts and innovative communities, a new phenomenon has emerged in the last ten years: global alliances and networks of networks which subscribe to transformative change at scale and organize around issues and themes across the globe (Waddell, 2016; Waddell et al., 2015). Inspired by the technological possibilities of the Internet both as information and meeting facility, coupled with an increasing community identifying as global citizens, they have emerged across continents. They take the form of alliances or networks around certain transformative issues they identify with collectively. This can range from regenerative agricultural practices to transformation research or to carbon-capture initiatives. Often, these are alliances or networks of organizations and individuals at the same time, and many of them span globally. Their occurrence is particularly important to understand how to gage the potential for transformations to regenerative civilizations. We argue that these alliances and networks of networks are not only vehicles to achieve both the 
scale and depth of transformations needed, but they are at the same time laboratories of the way future regenerative civilizations may function. Networked action is a patterned constellation that mirrors dynamic life structures much more than the ordinary, most often clearly delineated and hierarchical institutional set-up. It is generally built on respecting differences in identities, on participation and nonhierarchical interaction as well as on collaborative approaches. A brief look into the history of the emergence of these potentially transformative structures helps to identify key elements of pathways to regenerative civilizations.

\subsection{Trajectories Toward Transformative Systems Change}

Such networks and collaboration have always been a driving force behind civilizing human development, from the abolishment of slavery to international negotiations for global climate agreements. Yet, despite the many networked activities, transformations to sustainability are slow, and transformative actions to regenerative civilizations are still niche activities. It is interesting to note that since the advent of the concept of sustainable development in the Brundtland report (Brundtland, 1987), not only the focus of what is seen as societal progress has changed, but also the ways of working toward change. In the last decade of the twentieth century efforts to further sustainable development was mainly seen as a task of development agencies and governments. Many efforts, with the best of all intentions to achieve the millennium development goals took place in silo approaches as fragmented or isolated activities, often duplicating efforts and in competition for funding sources. Enormous effort went in designing projects that needed to show linear cause and effect to achieve what was considered a targeted impact - the improvement of a situation, for example, the income of a certain part of a population, or the rehabilitation of the environment. Participation of stakeholders and target groups in the design of projects were high on the agenda, but often failed to take into account that sustainability and development challenges showed up as definable problems, yet were the result of a constellation of multiple conditions, factors and trends that escaped the linear cause-effect project planning. Moreover, societal sectors were neatly delineated in their efforts to change: they operated according to their institutional identities as public sector, private sector and civil society. With the new millennium emerging, the approaches began to change. Gradually, the idea of increasing effectiveness through collaboration between different societal actors took root. Not astonishingly, this was a consequence of realizing that complex challenges require complex approaches. Systems thinking, which had been for so long on the fringe of societal and global development took root in its various forms as more actors became aware that complexity and interdependence required new approaches to change. More practically, experiments with pioneering cross-sector initiatives began, for example, in the introduction of social and environmental standards into commodity value chain such as coffee, tea, cocoa, palm oil or more recently textiles (Kuenkel, 2019; Kuenkel et al., 2020). Such multistakeholder initiatives opened up exciting avenues for societal and global learning. 
Civil society actors approached collaborations with companies to green their production, governments entered into partnerships with the private sector and acknowledged the important advocacy role for sustainability of civil society. Companies, also driven by the emerging concept of corporate sustainability began to embrace the idea that societal development, environmental compliance and economic performance need to go together. An unprecedented opportunity for societal learning emerged with the attempts to overcome sectoral and institutional silos. With the final agreement on the 17 Sustainable Development Goals in 2015, and the goal no 17 "Partnerships for the Goals" the new collaborative approach received additional credibility (United Nations, 2014). Multi-actor-partnerships have gradually become the new norm in approaches to tackle complex sustainability challenges which no one actor can solve alone even if there is still a lot of learning going on to make them successful (Kuenkel et al., 2020). Partnerships, or more general stakeholder collaboration has been established for water resource management, sustainable value chains, addressing ocean acidifications, sustainable city development or introducing national circular economy strategies.

The decisive step which is important to understand for transformation literacy, is that these partnerships and collaborative initiatives began to knit new communicative and action-oriented structures into the given institutional arrangements. While in the last decade of the twentieth century it was certainly strange to sit at the same table with company representatives, civil society activities and government officials, today, this is perfectly normal. While these multi-stakeholder partnerships have not always been easy to implement and may have had questionable results, they contributed to cross-societal learning, to overcoming stereotyped thinking and to developing new working relationships across societal sectors (Bierman et al. 2007; Kuenkel et al., 2020), which is a prerequisite for the collaborative capacity pro-active transformations need. Meanwhile, and partly parallel, the above-mentioned networks and alliances emerged. Some are composed of intentional communities of people and institutions who pursue the same sustainability goals in their different practices, others are deliberate networks of actors that intent to accelerate change in institutions at scale. Their purpose is to influence institutional and political actors in many entities across the globe at the same time. Often, they create meta-collaborations between existing initiatives and networks. Hence, they, again, create dynamic, new, non-hierarchical, cross-sectoral and complex structures that bring forward transformative change across and within the existing institutional set-up. These multistakeholder transformation networks are at the forefront of pathways to regenerative civilizations, because they model many aspects of future societies, that will be crucial for the way such societies will operate, such as complex adaptive structures, broad strategizing and joint responsibilities. They allow for fast communication across silos and institutional boundaries. Subsequently, they are able to adapt and adjust strategies more quickly; or, they develop strategies, information and action plans collectively in communication loops, which are non-hierarchical and allow for co-created results, and contextualized implementation in different areas. They have the potential to enliven not only their own members to experience that co-creating future is possible, but also bring the vision of regenerative civilizations into existing institutions. 
These networks of networks and alliances are laboratories for a regenerative future and do what the systems thinker Alexander suggested as knitting the new way of creating life into the existing structures. He suggested that, conceptionally, we need to learn from nature, which preserves certain structures, but grows organically into more and more complexity (Alexander, 2005). In this sense, an evolutionary approach to transformations acknowledges the overall composition and structure of the existing system, but reinforces or amplifies avenues for change through the emergence of networked structures. Transformations have always been and will also in future to a certain degree be structure-preserving transformations (ibid.). Disruptions are important, as they bring perturbations into a system, without which systems do not change or transform structurally (Maturana \& Varela, 1991; Prigogine, 1996). The case of Greta Thunberg and the Friday for Future Movement is a vivid example of such perturbations. Yet, the actual transformations, for example, the commitment to climate neutrality by all actors and its translation into societal narratives, policies, laws and regulations, are the actual steps that bring about transformations. This, then, needs to be translated in rearranged structural conditions as well as measurable targets. Disruptions, or perturbations are catalysts for change, if they get ignored, they wither, if they fall on a situation, in which many actors are ready for transformative change, they get enormously amplified. This is where networks play an important role-in creating the readiness for change, in amplifying disruptive change and in anchoring change in the institutional set-ups. Actors driving transformations in collaborative networks need to be clear in their purpose to contribute to increasing vitality of smaller and larger systems, from the individual to the globe, socially and ecologically.

Stewarding transformative change in patterns of collaborative networked action will sooner or later become the main and conscious managerial task of politicians, administrators, companies, societal actors and citizens. Only cross-sectoral and crossinstitutional structures can cope with the speed that sustainability transformations require. But there is a next step on the horizon of the trajectories toward transformations for which networked action as described above is the basis: the stewardship of transformation systems. The complexity of sustainability challenges is coupled with the insight that loosely coordinated intentional and collaborative systems of actors from within and outside institutional structures need to work together in a complementary way. Today, the many initiatives that operate globally begin to connect with each other, but tend to stay oblivious to understanding themselves as loosely connected parts of transformation systems. These interventions need to be implemented in appreciative acknowledgment of each other, without centralized coordination, and they also need to function as a collective learning system. Figure 15.1 shows the trajectories of emerging forms of networked and collaborative action toward stewarding transformative and structural systems change. Of course, the periods overlap: there are still many isolated projects happening driven by institutional or sectoral silos, and only few countries have adopted a collaborative multi-stakeholder partnership approach to overcoming sustainability challenges. But the trends are clear: pathways to regenerative civilizations require networked action and large systems change requires the stewarding of complex transformation systems 


\begin{tabular}{|c|c|c|c|}
\hline $1990-2000$ & $2000-2015$ & $2015-2022$ & 2022 - onwards \\
\hline $\begin{array}{l}\text { FRAGMENTED PROJECTS AND } \\
\text { INITIATIVES }\end{array}$ & $\begin{array}{l}\text { MULTI-STAKEHOLDER } \\
\text { INITIATIVES AND } \\
\text { PARTNERSHIPS }\end{array}$ & $\begin{array}{l}\text { MULTI-STAKEHOLDER } \\
\text { TRANSFORMATION } \\
\text { NETWORKS }\end{array}$ & $\begin{array}{l}\text { MULTI-ACTOR } \\
\text { STEWARDSHIP OF } \\
\text { TRANSFORMATION } \\
\text { SYSTEMS }\end{array}$ \\
\hline $\begin{array}{l}\text { Targeted isolated action } \\
\text { - Often competitive } \\
\text { Largely under the } \\
\text { control of one actor } \\
\text { (Government, NGO or } \\
\text { corporation) }\end{array}$ & $\begin{array}{l}\text { Complex collaboration } \\
\text { ecosystems to address } \\
\text { wicked problems } \\
\text { - Issue-based multi- } \\
\text { stakeholder } \\
\text { collaboration } \\
\text { - Regionally focused } \\
\text { collective impact } \\
\text { initiatives } \\
\text { Multi-actor partnerships }\end{array}$ & $\begin{array}{l}\text { Meta-collaboration } \\
\text { between networks } \\
\text { - Networks of people or } \\
\text { institutions with networks } \\
\text { or collaboration } \\
\text { initiatives } \\
\text { - Complementary } \\
\text { collective action action } \\
\text { - Collective stewarding of } \\
\text { transformative change }\end{array}$ & $\begin{array}{l}\text { Large systems change } \\
\text { using transformative } \\
\text { designs } \\
\text { - Complementary aligned } \\
\text { institutional and multi- } \\
\text { stakeholder action } \\
\text { - Collective stewarding of } \\
\text { transformation patterns } \\
\text { across sectors and } \\
\text { issues }\end{array}$ \\
\hline Limited impact & Improved collective impact & Transformative impact & $\begin{array}{l}\text { Transformative and structural } \\
\text { systems change impact }\end{array}$ \\
\hline
\end{tabular}

Fig. 15.1 Trajectories toward transformative systems change (copyright by the author)

with many institutional and non-institutional actors involved. Yet, I believe, we are only at the beginning to understand what it really means to build and leverage transformation systems for the transformative and structural systems change our planet and humankind needs.

\subsection{The Stewardship Task as a Patterned Transformation Approach}

It is apparent that stewarding transformations and advancing pathways to regenerative civilizations are a collective task, implemented across entire stakeholder landscapes. This raises issues that tend to be pushed into the background - the need for increased human capabilities to deal with complexity, uncertain processes and volatile social, political and environmental dynamics. Stewarding transformative systems change takes place at the edge of chaos, the precise area, where learning and the potential for change is greatest (Kauffman, 2016). But also, where dangers are high-oscillating between the urge to keep the old order in place and the threat to drown in the chaos. The sweet spot of transformative resilience lies between order and chaos. This means that the ability to hold high degrees of ambiguity, uncertainty and complex dynamics is a faculty which actors who aspire to transformative efforts must learn. The only possible trajectory to the resilience needed that will help to bear the chaos and restructure the old order into a new order, is to apply a form of systems thinking that respects diversity, acknowledges plural approaches and accepts non-simultaneity. It has taken a long time for systems thinking to leave the scientific niches and settle into the practice of doing change.

Taking the perspective of transformation systems invites us to take care of the many small and large change efforts that already exist. Pathways to regenerative 
Table 15.1 Overview: strategic core approaches of transformation literacy

\begin{tabular}{l|l}
\hline Collective stewardship & $\begin{array}{l}\text { The pro-active engagement for a regenerative future takes place } \\
\text { collaboratively by many complementary actors without centralized } \\
\text { control. Mutually supportive strategies towards safeguarding planetary } \\
\text { and human wellbeing at different levels of the global society connect in } \\
\text { transformation systems }\end{array}$ \\
\hline Visionary multiplicity & $\begin{array}{l}\text { The strategic acceptance that the potential of humankind's future lies in } \\
\text { its diversity allows for plural approaches to the quality of life as an } \\
\text { underlying principle of regenerative civilizations. There cannot be one } \\
\text { vision that fits all circumstances and contexts. The broad agreement on } \\
\text { properties of regenerative civilizations allows for a plurality of } \\
\text { interpretations and manifestations to be anchored in the political and } \\
\text { institutional landscape }\end{array}$ \\
\hline Network leverage & $\begin{array}{l}\text { Network leverage crosses boundaries to make use of the power and } \\
\text { influence of the variety of actors involved in networks, alliances, } \\
\text { movements or communities. Bridges between pioneering niche } \\
\text { initiatives and the institutional landscapes create leverage to influence } \\
\text { and finally shift structures and strategies of existing institutions }\end{array}$ \\
\hline
\end{tabular}

civilizations are organic processes that involve multiple approaches and practices. They are decidedly nonlinear based on multiple visions of regenerative civilizations that require translation into different contexts. There is no "one right way" to drive transformations. The more freedom there is to experiment with pioneering the future, the higher is the potential that transformative change happens. Yet, the experiments need to be exposed to collective learning, and ultimately, they need to be integrated in both existing and new structures. For the enhancement of transformation literacy this means that actors from within and outside institutions need to become familiar with new approaches that tune into the emerging trend of dealing with the complexity of transformations in a more effective way. There are three strategic core approaches that require conscious attention in transformation literacy: Collective stewardship as the pro-active engagement for a regenerative future in mutually supportive strategies; visionary multiplicity as the acknowledgment of plural approaches to the quality of life as an underlying principle of regenerative civilizations; and network leverage as the deliberate and reflective use of power and influence across sectors and institutions. While Table 15.1 shows an initial overview of these the strategic core approaches of transformation literacy, the following sections will explore them in more detail.

\subsubsection{Collective Stewardship}

The first strategic core approach of transformation literacy is to embrace the nonlinearity of transformative change and take a collective stewardship approach to foster socio-ecological interaction patterns that model how an alive, resilient and regenerative future should look like. Cause-effect analysis and planning will always be important, yet they need be coupled with fast collective learning and the acceptance of 
the essential patterned complexity of transformative change. Collective stewardship is different from steering and requires the pro-active and collaborative engagement for a regenerative future by many complementary actors without centralized control. Mutually supportive strategies and multiple pathways align around a sense of responsibility for safeguarding planetary and human well-being at all levels of the global society. Such collective stewardship approaches can be issues-based, such as driving the widespread adoption of climate neutrality, regenerative food systems or circular economy practices across an entire stakeholder landscape; or they can be placebased, such as stewarding transformations for multiple issues within a certain circumcised area. Examples are multi-stakeholder strategies toward regenerative cities that involve multiple social, ecological and technological issues, or the adoption of a well-being economy approach in a country. Naturally, these approaches are more holistic and can be built on strong community identification. They work best, if the entities are not too large, for example at small country level, city level, district level or community level. Inevitably, both approaches need to go hand in hand: issuebased approaches are less holistic, but can be implemented at a larger scale (e.g., switch to renewable energies, or climate neutrality), yet they may be fragmented as they leave out the complexity of issues (e.g., biodiversity loss or social cohesion). Geographically- or place-based approaches are more systemic, yet they may hit the wall when it comes to conditions set by the larger system which determines conditions for transformations (e.g., effects of national policies that undermine regenerative city efforts). Hence, both approaches of collective stewardship are inevitably enshrined with each other.

\subsubsection{Visionary Multiplicity}

The second strategic core approach of transformation literacy is to embrace visionary multiplicity. It is important to foster agreements about the vision of future regenerative civilizations, and also anchor them in the current political and institutional landscape. The increasing use of narratives that describe a future with renewable energy, social equity and healthy ecosystems are testimony to an emerging shift that furthers visions of regenerative civilizations in the global communities of change-makers. The increasing use of terms like eco-civilization, regenerative cities, regenerative agriculture, agroecology, or well-being on a healthy planet, etc. shows the shift in thinking that is happening. Yet, it is important to consider that there cannot be one vision that fits all circumstances and contexts. Images of the future and goals are transformational guidance rather than an end state to be reached. The vision of a regenerative future should never be so tight that it will not allow for a plurality of interpretations and manifestations. The potential of humankind's future lies in its diversity and the plural approaches to the quality of life as an underlying principle of regenerative civilizations. Setting goals, defining transformative impact and creating measurable targets are crucially important. Such goals are contextualized transformative guidance for a range of targets for which interconnections, interdependencies 
and impact need to be continuously crosschecked. Embracing a plurality of visions in transformation literacy means to identify properties of future regenerative civilizations that as many people as possible can agree on, and using them as a frame, within which many different visions can emerge and manifest. Transformative action at the pace and scale needed requires self-organization and self-efficacy in decentralized or distributed initiatives.

\subsubsection{Network Leverage}

The third strategic core approach of transformation literacy is to leverage networks, alliances, movements and coalitions, as well as their connections so that they form a deliberate transformation system. The Internet-based communicative possibilities have greatly advanced the proliferations of communities of change, even though we may still have to work hard to overcome silo mentalities and competition in transformation efforts. But network leverage is more than staying within a community of like-minded actors pursuing the same goal. It acknowledges patterned, complementary and nested change initiatives and it means crossing community boundaries to make use of the power and influence of the variety of actors involved in the networks, alliances, movements or communities. Because it is the capability to create bridges between pioneering niche initiatives and institutional landscapes, which creates the leverage. Hence, network leverage will increasingly also come from actors within the existing institutions with the intention to transform these institutions. The human capability to co-create future is unprecedented, if not blocked and deadened by outdated structures and the clinging to power of people who claim the past as the future. Network leverage is the route to dismantling such outdated power structures, when actors in networks are able to influence and finally shift structures and strategies of existing institutions. Evenly important is to transition from loosely organized network and alliance toward becoming part of the institutional landscape. The institutionalization of networks as a form of meta-structures with influence on the system might not always be the route to take, because it often means that dynamic structures solidify and are more difficult to adapt, but it is important to keep in mind that eventually, new structures that take well-being on a healthy planet to heart, are the cornerstone of a transformed future.

\subsection{Multiple Transformative Approaches}

In the complexity of transformative systems, change with multiple actors in diverse places and various institutions who have different interests and capabilities, it is important to recognize that no one network, movement or alliance can solve the multi-faceted sustainability problem because of their very embeddedness. Multiple 
contributions, all referring to the broad vision of properties of a regenerative civilization are the pathway to better functioning, more vital systems. No matter how small or large change initiatives are, they are evenly important, because multiple small system change is the cornerstone of large systems change (Hinrichs \& Kangas, 2003; Waddell et al., 2015). Transformation literacy integrates complementary approaches:- from technical to social to cultural to economic (Schneidewind, 2013). It is built on the understanding of essential features of life's processes which guide evolutionary processes. The design of transformative change needs to reach people's hearts and minds-because this is the pathway to dynamic and self-driven change in behavior. The agent of change is human, hence leveraging human competencies is central to the acceleration of change. The contributions of part three therefore encompass a range of different approaches to transformations.

Chapter 16 by Mariana Bozesan looks at how mind shifts can turn into transformation leadership. She notes that in spite of the enormous efforts trying to address the COVID-19 pandemic, humanity is still struggling to come together in a collective effort to address the existential threats posed by the grand global challenges. The current pandemic and the assault on democracy, which culminated in the US Capitol riot on January 6th, 2021, are only the latest in a series of obvious challenges facing humanity in the disruption era. Beyond the existential threats to planetary integrity that the climate crisis posits, there is a crisis in consciousness. Yet we are currently witnessing a noteworthy mind shift that is actively changing outdated systemic structures to accommodate the necessities of the new global reality and regenerative futures. Spurred into action by personal emergencies, a whole host of consciousness leaders from all areas of life including business, finance and philanthropy, to name a few, have surfaced as major players and seem to act more daringly in the world. This chapter will focus on (1) the circumstances that enable, facilitate and accelerate societal polarization; (2) revealing the underlying dynamics and the influencing factors that are at play in the current broken information ecology; (3) understanding when and how the mind shift toward unification can occur; (4) how we can harness and foster our astonishing human capacity to cooperate toward addressing current existential threats; (5) how we can become more aware of the many cognitive biases that twist our picture of reality and how we can learn to separate the truth signals from the fake noise.

Chapter 17 by the artist and curator Bente Elisabeth Endresen describes the transformative potential of arts and science collaboration. The aim of the Nordic art and science project "Red Snow-When the Climate Bleeds" which was undertaken in 2014-2016, was to increase people's awareness of the accelerating climate changes we are witnessing in the twenty-first century. This chapter shows how people can be encouraged to take action for the care of our planet and to live in a more sustainable way. The project was centered around an exhibition, consisting of artwork and scientific presentations, established collaboration with students at schools and universities and was implemented in four countries. In order to highlight the urgency of the need for change, the project showed some future scenarios presented by climate researchers and made the public aware, via neutral scientific information, of how current human activity is affecting the climate. With the use of visual art, music and 
dance, it was possible to reach a larger audience than science alone could: this opened people's hearts and minds to new knowledge. The chapter concludes that the collaboration between the arts and science is increasingly important. Art can successfully go beyond the mental mindset, and speak directly to the emotions of the audience, and once works of art have made an impression, visitors are generally more open to new impressions, new information and new knowledge.

Chapter 18 by Kora Kristof shows the skills required for transformation literacy. She reminds us that climate change and many other problems show clearly that fundamental change is necessary. However, many good ideas get stuck in implementation. Therefore, the question is how can change be orchestrated more successfully by many actors? We take sports courses or go to music lessons to learn, to get better quickly or to avoid hurting ourselves. Professionals in sport, art and other fields also receive intensive coaching from experts. However, when it comes to make successful progress toward sustainability, people often rely on "home recipes". It is time to become more professional in this area as well. To achieve this, it is important to make targeted use of the findings of transformation research and key success factors as well as to develop transformation literacy. In this chapter, the models of change approach is presented, which focuses on central success factors for social change and shows ways to successful drive transformations.

Chapter 19 by Ladeja Godina Košir and Petra Kuenkel take a deep dive into ways of strengthening transformations toward a Circular Economy in Europe. Extractive economies take resources, produce goods and drop waste, as if resource could never get depleted, and waste would not accumulate as environmental threat. Fortunately, the mindset shift is underway, not only because resources are increasingly getting scarce, while populations increase, but also because greenhouse gas emissions have reached a point which lets people begin to experience the volatility of the future. Yet, there is a tendency to believe, a Circular Economy is mainly about technology and recycling. But it is more than that: it includes many aspects of actions that lead to an overall regenerative operating system at the core of economic activities, such as product design, material and component re-use, recycling of materials, refurbishing, upgrading products, as well as regenerative energy production. Practitioner pioneers require support from governments, and without national strategies and roadmaps, pathways to regenerative future will be underutilized. This chapter looks at the need for collaborative approaches to transformative change. In an interview with an experienced promotor of Circular Economy approaches the most important strategies get highlighted, and the challenges elaborated. The chapter concludes with recommendations to governments on how to drive the transition toward Circular Economies.

Chapter 20 by Elisabeth Kuehn continues the deep dive into the practice of transformative change. She suggests that transformation literacy needs to incorporate the understanding that achieving the vision of vital and regenerative systems requires actors to drive change that models the future systems aliveness. Only then, she proposes, can they become successful transformation systems. Practical experience shows that the shift to transformative impact happens best in enlivening networks across systems, in what is called transformation networks. This chapter shows that 
a necessary systemic perspective on transformation network means they can and need to be strategically built. It introduces six transformation network enablers that support such strategic guidance in building networks, and who were used in two practical examples of setting up transformation networks. The first example is on the local level and looks at a network of youth civil society for Good Governance in central Tunisia. The second example is on the other end of the spectrum: It examines a global network of professionals toward a new economic future.

Chapter 21 by Petra Kuenkel explores how different actors in economic systems change can become part of a more coherent transformation system toward economic systems change that focuses on economies in service of life. The chapter suggests that this is greatly supported by understanding what gives life to systems and making this the guiding force of transformative efforts. It will introduce a combination of organizing principles for new economies that would safeguard planetary and human integrity, while allowing for different interpretation and manifestation. The role these principles play will be illustrated by the example of transformations in the energy sector. The chapter asks how actors who are part of a transformation system toward new economies can more consciously steward the change collectively by leveraging strategic drivers. It elaborates six of these drivers as entry points for collaborative systemic change, and briefly illustrates the strategic application of these drivers in the energy sector transformation. It concludes with deliberations on how to use the principles and drivers to accelerate economic systems change toward a new operating system, in which planetary life support systems are as much valued as the dignity of people.

Chapter 22 by Ndidi Nnoli-Edozien explores the mindset humanity needs to develop in preparation for an emerging future, from an African perspective. The required human consciousness, and inevitable change toward it spoken of within this chapter, must be holistic and encompassing, bridging the gap between thought and action, linking the past to the present and the future, democratizing access, in moderation, to resources, eliminating waste and fostering regeneration. One opportunity in view is leveraging the power of emerging twenty-first century technology, specifically blockchain based decentralized financial (De-Fi) networks, because of their potential to build a global community where trust is once more a currency and where we can rely on humanity to do good for each other and for the planet. But, prior to investing in technology, we need a shared understanding that ensures our dreams are achievable without destroying the planet. We need to design solutions and approaches that enable all persons, especially those marginalized in emerging economies, to find their voices and fulfill their aspirations. The author makes a strong case for combining past wisdom with contemporary know-how to create a new future that is more inclusive and equitable. Drawing on African traditional philosophy and practices, learning from Ubuntu and the Igbo people, she explores the balance between individual rights and communal values. The chapter also offers insights into the SevenPillars framework that allows business interests, private and public, to thrive whilst safeguarding our natural ecosystem and upholding human dignity and equity. 


\section{References}

Alexander, C. (2002). The nature of order. An essay on the art of building and the nature of the universe: Book I - The Phenomenon of Life, Berkeley, CA: The Center for Environmental Structure.

Alexander, C. (2005). The nature of order. An essay on the art of building and the nature of the universe: Book III-A Vision of a Living World, Berkeley, CA: The Center for Environmental Structure.

Avelino, F., Wittmayer, J. M., O'Riordan, T., Haxeltine, A., Weaver, P., Kemp, R., Loorbach, D., \& Rotmans J. (2014). Gamechangers and transformative social innovation. The case of the economic crisis and tranformative social innovation. TRANSIT Working Paper, TRANSIT: EU SSH.2013.3.2-1 Grant agreement no: 613169.

Bateson, G. (2000). Steps to an ecology of mind. The University of Chicago Press.

Biermann, F., Man-san Chan, A. M., \& Pattberg, P. (2007). Multi-stakeholder partnerships for sustainable development: Does the promise hold? In Glasbergen, P., Biermann, F., \& Mol, A. (Eds.), Partnerships, governance and sustainable development: Reflections on theory and practice. Northampton, Massachusetts: Edward Elgar.

Brundtland, G. (Ed.). (1987). Our common future: The world commission on environment and development. Oxford University Press.

Hinrichs, K., \& Kangas, O. (2003). When is a change big enough to be a system shift? Small systemshifting changes in German and Finnish pension policies. Social Policy, \&amp; Administration, 37(6), 573-591.

Kauffman, S. (2016). Humanity in a creative universe. Oxford University Press.

Kuenkel, P. (2019). Stewarding sustainability transformations-An emerging theory and practice. Report to the Club of Rome. Springer Nature.

Kuenkel, P., Kuehn, E., Stucker, D., \& Williamson, D. F. (2020). Leading transformative change collectively. A practitioner's guide to realizing the SDGs. Routledge.

Loorbach, D., Avelino, F., Haxeltine, A., Wittmayer, J., O'Riordan, T., Weaver, P., \& Kemp, R. (2016). The economic crisis as a game changer? Exploring the role of social construction in sustainability transitions. Ecology and Society, 21(4), 15. https://doi.org/10.5751/ES-08761210415

Maturana, H. R., \& Varela, F. J. (1991). Autopoiesis and cognition: The realization of the living (Vol. 42). Springer.

Prigogine, I. (1996). The end of certainty: Time chaos and the new laws of nature. The Free Press.

Rotmans, J., \& Loorbach, D. (2010). Towards a better understanding of transitions and their governance: A systemic and reflexive approach. In J. Grin, J. Rotmans, \& J. Schot (Eds.), Transitions to sustainable development: New directions in the study of long term transformative change (pp. 105-222). Routledge.

Schneidewind, U. (2013). Transformative literacy: Understanding and shaping societal transformations. GAIA - Ecological Perspectives for Science and Society, 22(2), 82-86.

United Nations. (2014). The road to dignity by 2030: ending poverty, transforming all lives and protecting the planet. New York, NY, USA: United Nations. Retrieved June 23, 2017, from http://www.un.org/disabilities/documents/reports/SG_Synthesis_Report_ Road_to_Dignity_by_2030.pdf.

Verbong, G., \& Loorbach, D. (Eds.) (2012). Governing the energy transition: Reality, illusion or necessity? Routledge Studies in Sustainability Transitions, Band 4.

Waddell, S. (2016). Change for the audacious: A doers' guide to large systems change for a flourishing future. Boston, MA, USA: NetworkingAction.

Waddell, S., Waddock, S., Cornell, S., Dentoni, D., McLachlan, M., \& Meszoely, G. (2015). Large systems change: An emerging field of transformation and transitions. The Journal of Corporate Citizenship, 58, 5-30.

Weber, A. (2016). Biology of wonder: Aliveness, feeling and the metamorphosis of science. New Society Publishers. 
Open Access This chapter is licensed under the terms of the Creative Commons Attribution 4.0 International License (http://creativecommons.org/licenses/by/4.0/), which permits use, sharing, adaptation, distribution and reproduction in any medium or format, as long as you give appropriate credit to the original author(s) and the source, provide a link to the Creative Commons license and indicate if changes were made.

The images or other third party material in this chapter are included in the chapter's Creative Commons license, unless indicated otherwise in a credit line to the material. If material is not included in the chapter's Creative Commons license and your intended use is not permitted by statutory regulation or exceeds the permitted use, you will need to obtain permission directly from the copyright holder.

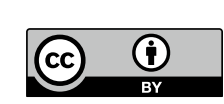

